\title{
A Brief Review on Citrullinemia Type1: A Urea Cycle Disorder
}

\section{Venkatesh HA*}

Consultant Neonatologist, Manipal Hospital, Bangalore, India

*Corresponding author: Dr. Venkatesh HA, Consultant Neonatologist, Manipal hospital, Bangalore, India, Tel: 919980135300; E-mail: Venkatveena46@gmail.com Rec date: Feb 28, 2014; Acc date: May 28, 2014; Pub date: May 30, 2014

Copyright: (C) 2014 Venkatesh HA. This is an open-access article distributed under the terms of the Creative Commons Attribution License, which permits unrestricted use, distribution, and reproduction in any medium, provided the original author and source are credited.

\begin{abstract}
Citrullinemia is an inherited urea cycle disorder with autosomal recessive inheritance. This condition was first described in the year 1962. Affected individuals will have marked elevation of citrulline in blood. It is due to defective enzyme arginosuccinate synthetase in the urea cycle path way. Affected infants show very high serum ammonia $(1000-3000 \mu \mathrm{mol} / \mathrm{L}$ against normal value of $<200 \mu \mathrm{mol} / \mathrm{L}$. There are two types of Citrullinemia. Citrullinemia Type 1 and Type 2, Type 1 Citrullinemia also called as classic Citrullinemia usually becomes evident in the first few days of life. Type 1 is the most common disorder affecting about 1 in 57,0000 people worldwide. Usually, clinical features appear between 24 and 72 hours of age, once the feed is established. Proper diagnosis, counseling the parents, prompt management including nutrition and immunization might save many lives. Some of the infants with severe forms of citrullinemia might require liver transplantation later.
\end{abstract}

Keywords: Citrullinemia; Arginosuccinate synthetase; Diagnosis; Nutrition; Immunization

\section{Introduction}

Citrullinemia is an autosomal recessive disorder that causes ammonia to accumulate in the blood. This belongs to a genetic disease called urea cycle defect. Two forms of citrullinemia have been described. Type 1 citrullinemia Type 1 is the most common disorder presenting in the first few days of life $[1,2]$. Affected infants typically appear normal at birth, but as ammonia level in the blood rises they develop symptoms. Citrulline levels in these infants can be 100s of times the normal values. Type 2 citrullinemia also called as Citrin deficiency results in limitation of activity for the enzyme argininosuccinic acid synthase. This defect can present with classic hyperammonemia in new born, intrahepatic cholestasis and fatty liver, but is more likely to present with insidious neurologic findings, hyperammonemia, hypercitrullinemia and hyperlipidaemia in adult hood. Confirmation requires molecular genetic testing by DNA analysis in the patient.

\section{Diagnosis}

The most important step in the diagnosis of urea cycle disorders is clinical suspicion of hyperammonemia. Main clinical features include poor feeding, vomiting, lethargy, respiratory distress, seizures, if not detected and treated, early death may ensure. A blood ammonia level is done in evaluating the patient with suspected Urea cycle disorder. Other markers useful in the diagnosis include $\mathrm{pH}, \mathrm{CO}_{2}$, the anion gap, blood lactate. Plasma acyl carnitine, Plasma and urine, amino acids and determination of orotic acid. An elevated plasma ammonia level of $150 \mu \mathrm{mol} / \mathrm{L}$ or higher in neonates and more than $100 \mu \mathrm{mol} / \mathrm{L}$ in older children and adults, associated with a normal anion gap and a normal blood glucose level, is a strong indication for the presence of a urea cycle defect. The findings of Hyperammonemia and elevated Citrulline in the new born screen dried blood test of the patient suggested one of two metabolic defects; Argininosuccinic Acid Synthetase Deficiency (ASAS) or Argininosuccinate lyase deficiency
(ASAL). Molecular genetic testing by DNA analysis pinpoints the diagnosis.

Quantitative plasma amino acid analysis can be used to evaluate these patients and arrive at tentative diagnosis. Imaging the brain in babies with hyperammonemia may show changes in the brain as the elevated ammonia and glutamine accumulation in the brain causes astrocyte swelling and encephalopathy [3]. Figure 1 depicts MRI changes in a baby with Citrullinemia presented to us at 1 year of age with seizure showing areas of hyper intensity at frontal, posterior parietal and posterior temporal lobes.

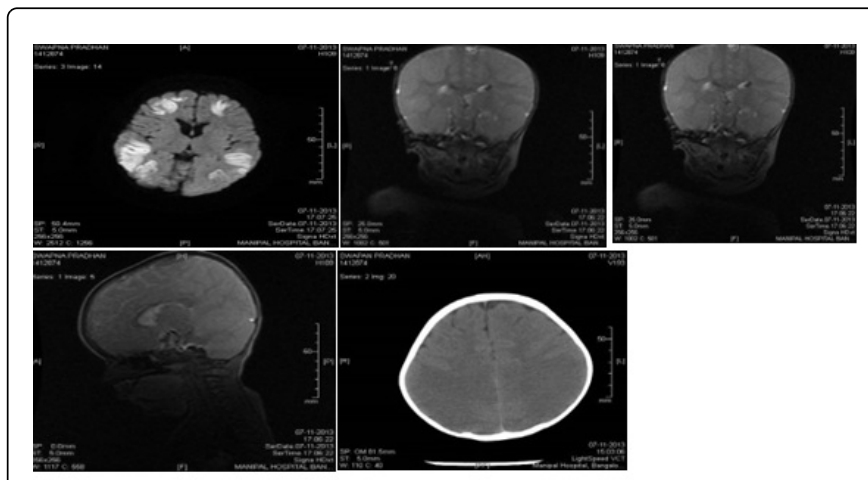

Figure 1: T2 weighted hyper intensity signal involving bilateral frontal, posterior parietal and posterior temporal lobes on MRI

\section{Differential Diagnosis}

Lethargy is a common presentation in infants presenting at emergency room. It is essential to know the different causes for lethargy. The list of causes is represented by a pneumonic -THE MIS FIT for describing the differential diagnosis of critically ill neonates [4]

\section{T-Trauma}

H-Heart anomalies - Hypo plastic left heart syndrome 
Page 2 of 3

E- Endocrine problems-Hypothyroidism, Congenital adrenal Treatment hypoplasia

M-Metabolic- electrolyte imbalance, Hypocalcemia, hypercalcemia

I-Intestinal obstruction - Volvulus

S-Sepsis

F-Feeding catastrophes- Over feeding and under feeding

I-Inborn error of metabolism

T-Toxins- Phenobarbitone toxicity
Treatment includes the immediate management and specific management. Emergency management includes stabilization of airway, dextrose and electrolyte fluids to mitigate catabolism and typical dehydration, antibiotics and septic work up to treat sepsis, possible transport to treatment capable institution as soon as possible, establishing Central venous access and providing physiological supports (pressers, buffering agents). Treatment of acute hyperammonemia in an infant is given in the Table 1.

1. Provision of adequate calories, fluid and electrolytes intravenously $(10 \%$ glucose, $\mathrm{NaCl}(0.45 \%$ to $0.9 \%)$ and intravenous lipids $1 \mathrm{~g} / \mathrm{kg} / 24 \mathrm{hours}$. $0.25 \mathrm{gm} / \mathrm{kg} / 24 \mathrm{hr}$ of protein as a mixture of essential amino acids during first $24 \mathrm{hr}$ of therapy

2. Sodium benzoate $250 \mathrm{mg} / \mathrm{kg}$,sodium phenylacatate $250 \mathrm{mg} / \mathrm{kg}$ and Arginine hydrochloride $200-600 \mathrm{mg} / \mathrm{kg} / 24 \mathrm{hr}$ are added to $20 \mathrm{ml} / \mathrm{kg}$ of $10 \% \mathrm{glucose}$ and infused with in 1-2 hours

3.Continuous infusion of sodium benzoate $(250-500 \mathrm{mg} / \mathrm{kg} / 24 \mathrm{hr}$.), phenyl acetate $(250-500 \mathrm{mg} / \mathrm{kg} / 24 \mathrm{hr})$ and arginine $200-600 \mathrm{mg} / \mathrm{kg} / 24 \mathrm{hr}$ after adding to the daily intravenous fluid

4. If the above medical line of therapy fails to bring down serum ammonia level peritoneal dialysis or hemodialysis is initiated

Table 1: Treatment schedule of acute hyperammonemia in an infant (Source; chapter 79. Defects in metabolism of amino acids from Nelson textbook of pediatrics)

Specific medication for hyperammonemia includes sodium benzoate and phenyl acetate [5]. Sodium benzoate combines with glycine to make hippuric acid and sodium phenyl acetate combines with glutamine to make phenacetylglutamine and which are excreted in the urine. Arginine must also be administered as it replenishes circulating amino acid levels. Higher dose is required in the management of citrullinemia. Fluid and electrolytes should be optimized to maintain normal intracranial pressure. Dialysis if medical management fails is very effective for the removal of ammonia.

Ammonia clearance with peritoneal dialysis is only approximately $1 / 10^{\text {th }}$ of that of Continuous arteriovenous dialysis and is not recommended for the specific Urea cycle enzyme defect therapy in the new born period. (CAVH) has the added benefit of not being administered intermittently and thus avoiding the major swings in intravascular volume that may exacerbate an already catabolic state. Exchange transfusion is not recommended usually, as it removes ammonia only from intravascular compartment [6-8]. If the basic defect is severe enough, liver transplantation should be considered at appropriate time after the consultation with hepatologist.

\section{Communication}

Parents should be made to understand the severity of the problem and the need for life long treatment.

Long term management includes low protein diet, essential amino acid supplementation, vitamin and mineral supplementation, medications to increase waste nitrogen excretion, caring for special situations and provision of emergency regimen in inter current illness and liver transplantation in selected candidates.

A multidisciplinary approach involving pediatrician, developmental pediatrician, neurologist, metabolic disease expert, dieticians and hepatologist is corner stone in the long term management.
Avoiding inter-current infections and immunizing the child in time is very important in avoiding exacerbations.

\section{Nutritional Management in Citrullinemia}

Nutritional management is one of the most challenging issues in urea cycle disorder [9]. The requirement mainly depends upon variables like specific enzyme defect, age related growth rate, current health status, level of physical activity, amount of amino acids administered, residual urea cycle function, energy intake, family lifestyle. A low protein diet is recommended and emphasis should be on other non-protein caloric sources in children with citrullinemia. Supplementation with special amino acid formulas (like cyclinex, Prophree) should be considered. Family should be educated in management of complex very low protein diet.

\section{Vaccination}

Children with inherited metabolic disorders are potential high risk group for vaccine preventable diseases. According to results of a retrospective study from a large health care system presented in 2009 at the infectious disease society of America all vaccines are recommended unless the condition is associated with immunodeficiency where live-vaccines are contraindicated. Preferably vaccination should be done under medical supervision [10].

\section{Genetic Counseling}

Citrullinemia like any other inborn error of metabolism needs genetic counseling. It is inherited as an autosomal recessive disorder. Carrier testing for at risk relatives and prenatal diagnosis are possible. Mutation of ASS1 gene cause Type I citrullinemia. This gene provides instructions for making an enzyme, arginisucccinate synthase 1 that is responsible for the third step of the urea cycle. At least 50 mutations that cause type 1 citrullinemia have been identified in the ASS1 gene. 
Citation: Venkatesh HA (2014) A Brief Review on Citrullinemia Type1: A Urea Cycle Disorder. J Neonatal Biol 3: 143. doi: 10.4172/2167-0897.1000143

Page 3 of 3

Location of the ASS1 gene is on the long arm of chromosome 9 at position 34 [1].

\section{Conclusion}

Citrullinemia, a urea cycle disorder is an infrequently seen common problem. It should always be considered in the differential diagnosis in any sick infant. Multidisciplinary approach is crucial in the management.

\section{References}

1. Msall M, Batshaw ML, Suss R, Brusilow SW, Mellits ED (1984) Neurologic outcome in children with inborn errors of urea synthesis. Outcome of urea-cycle enzymopathies. N Engl J Med 310: 1500-1505.

2. Martin JJ, Farriaux JP, De Jonghe P (1982) Neuropathology of citrullinaemia. Acta Neuropathol 56: 303-306.

3. Bindu PS, Sinha S, Taly AB, Christopher R, Kovoor JM (2009) Cranial MRI in acute hyperammonemic encephalopathy. Pediatr Neurol 41: 139-142.
4. McCollough M, Sharieff GQ (2002) Common complaints in the first 30 days of life. Emerg Med Clin North Am 20: 27-48, v.

5. Gupta N, Kabra M (2011) Acute management of sick infants with suspected inborn errors of metabolism. Indian J Pediatr 78: 854-859.

6. Westrope C, Morris K, Burford D, Morrison G (2010) Continuous hemofiltration in the control of neonatal hyperammonemia: a 10-year experience. Pediatr Nephrol 25: 1725-1730.

7. Todo S, Starzl TE, Tzakis A, Benkov KJ, Kalousek F, et al. (1992) Orthotopic liver transplantation for urea cycle enzyme deficiency. Hepatology 15: 419-422.

8. Tu W, He J, Dai F, Wang X, Li Y (2012) Impact of inborn errors of metabolism on admission in a neonatal intensive care unit--a prospective cohort study. Indian J Pediatr 79: 494-500.

9. Singh RH (2007) Nutritional management of patients with urea cycle disorders. J Inherit Metab Dis 30: 880-887.

10. Infectious Disease Society of America (IDSA) (2009) 47th Annual meeting: Abstract 187. 